Revista Destaques Acadêmicos, Lajeado, v. 10, n. 4, 2018. ISSN 2176-3070

DOI: http://dx.doi.org/10.22410/issn.2176-3070.v10i4a2018.2030

http://www.univates.br/revistas

\title{
CONCEPÇÃO DA ESTRUTURA DO APARATO DE PROTEÇÃO AO OVO (APO), CONFORME A COMPETIÇÃO DO IBRACON
}

\author{
Adriana Inéia ${ }^{1}$, Chanalisa Ruggini Salvi ${ }^{2}$, Amanda Revoredo ${ }^{3}$, \\ André Luis Sfoglia ${ }^{4}$
}

Resumo: O presente estudo apresenta uma concepção do pórtico desenvolvido para competição do $11^{\circ}$ CCTEC da Universidade do Vale do Taquari UNIVATES. O principal objetivo do artigo consistiu em colocar em prática os conceitos internalizados durante a disciplina de Estruturas de Concreto Armado II, a fim de obter êxito no preparo, execução e ensaio do APO. Nessa perspectiva, tendo como plano de fundo, a submissão de um caso real de responsabilidade da profissão de engenheiro civil. No que se refere ao projeto experimental, o Aparato de Proteção ao Ovo foi desenvolvido seguindo rigorosamente as normas do IBRACON (Instituto Brasileiro de Concreto), posteriormente submetendo o pórtico ao ensaio de compressão e carregamento dinâmico, na qual a cada golpe recebe-se um acréscimo de carga até a sua ruína. Para validação do estudo todo o comportamento desde o projeto, execução até as causas da ruptura foram analisados, tendo como fundamento o de melhorar o protótipo para torna-lo mais competitivo para um futuro trabalho ou estudo.

Palavra-chave: Concreto armado. Concreto pós-reativo. Concreto de alto desempenho.

\section{Introdução}

Esse estudo do APO foi proposto na disciplina de Estruturas de Concreto Armado II. Sua principal finalidade é de simular uma situação real

1 Engenheiro civil, diplomado pela Universidade do Vale do Taquari - Univates. Pós-graduando da Pontifícia Universidade da Católica do Rio Grande do Sul PUC-RS, nos cursos de MBA - GEM (Gestão, empreendedorismo e marketing) e da pós-graduação em FIB - Finanças, investimentos e banking.

2 Engenheira civil, diplomada pela Universidade do Vale do Taquari - Univates. Mestranda da FEUP - Faculdade de Engenharia da Universidade do Porto.

3 Engenheira civil, diplomada pela Universidade do Vale do Taquari - Univates.

4 Formando do curso de engenharia civil da Universidade do vale do Taquari - Univates. 
que induza a utilização de todos os princípios teóricos explanados em aula. Nessa perspectiva, a essência do trabalho foi propor um elemento estrutural resistente aos impactos de cargas dinâmicas induzidas no sentido vertical, aproveitando ao máximo a composição concreto/aço.

As normas que regularizam o trabalho são originárias do IBRACON (Instituto Brasileiro de Concreto). O desenvolvimento deste estudo teve impacto direto com a formação acadêmica dos alunos envolvidos. Pois, novas fontes tiveram que ser consultadas para resolver limitações como a falta de experiência profissional e a busca por novos materiais visando diminuir patologias corriqueiras. Além disso, a pesquisa permitiu uma aproximação do lado tecnológico e laboratorial da engenharia civil. Com o auxílio da literatura, pode-se agregar conhecimento, no que se refere à utilidade de diferentes materiais, adotando assim, um traço do tipo Concreto Pós-Reativo (CPR), composto para este caso o cimento Portland $\mathrm{CP} V$, a areia natural média, o pó de quartzo, a sílica ativa e as fibras de prolipropileno.

$\mathrm{O}$ grupo $\mathrm{CA}^{3}$ tem como objetivo, propor um pórtico que tenha ductilidade suficiente para resistir, aos impactos verticais de carga dinâmica de um cilindro de diâmetro de 15 (mm) nas alturas de 1, 1,5, 2, 2,5 (m) .Portanto, o plano de fundo do artigo é desenvolver um traço de concreto resistente o suficiente para resistir a estas solicitações, tendo como desafio dimensionar a armadura de maneira mais resistente e empregar materiais que aumentem a ductilidade mistura concreto/aço.

\section{Programa experimental}

Nesta seção apresentam-se as especificações dos materiais e o traço empregado no estudo e, a seguir, a metodologia utilizada.

\subsection{Materiais}

$\mathrm{O}$ concreto empregado nesse estudo foi o CPR, por apresentar alta resistência em seções reduzidas. Os componentes são cimento Portland CP V, areia média, pó de quartzo, sílica ativa, aditivo superplastificante e fibra de prolipropileno. O cimento empregado no APO é o CP V / ARI de alta resistência inicial, com sua massa específica de $2,97 \mathrm{~g} / \mathrm{cm}^{3}$, já areia utilizada é de origem natural do tipo quartzosa, isenta de matéria orgânica, módulo de finura (MF) 2,15, absorção 0,43 e massa específica de $2,53 \mathrm{~g} / \mathrm{cm}^{3}$ (Ineia, 2017)

No estudo, também foi empregado o aditivo superplastificante Tec Flow 8000. Esse aditivo possui alta eficiência de redução do teor de água, quando comparado com outros. Para reforçar o (APO), foram incorporados ao concreto fibras de prolipropileno que tem baixo preço e características especificas. Uma de suas principais propriedades é a cadeia polimérica, que interfere positivamente na resistência e comportamento do concreto, outras peculiaridades são a sua natureza plástica, sendo inodoro, incolor e atóxico. 
O aço motivo de estudo neste artigo é o de tipologia mola. Por atender as necessidades do estudo, entre os seus principais benefícios estão o controle das fissuras, alta durabilidade, maior resistência ao impacto e à fadiga e o aumento da capacidade de deformação (ductilidade de tenacidade). A sílica ativa usado é da Dow Corning, seu emprego se deu por diminuir a permeabilidade e aumentar a resistência. Seu efeito no concreto é de microfíler, tornando-o mais homogêneo e uniforme, já as suas especificações são, massa específica 2,20 g/ $\mathrm{cm}^{3}$, massa unitária de 200 a $300 \mathrm{Kg} / \mathrm{cm}^{3}$ e diâmetro médio de $0,1 \mu \mathrm{m}$ (tudo indicado pelo fabricante).

$O$ traço adotado para esse experimento se origina da bibliografia, sendo de autoria de Soto (2014). Mas, o grupo $\mathrm{CA}^{3}$ fez adaptações como a redução da água e adição de pó de quartzo e fibra de prolipropileno visando o aumento da resistência, a composição do traço se encontra a seguir na Tabela 01.

Tabela 01 - Composição do traço em massa.

\begin{tabular}{c|c|c|c|c|c|c}
\hline \multicolumn{7}{c}{ Composição do traço } \\
\hline & CP & Areia & $\mathrm{H}_{2} \mathrm{O}$ & Sílica ativa & Pó de quartzo & Superplastificante \\
\hline CPR & 1 & 1,1 & 0,44 & 0,15 & 0,23 & 0,08 \\
\hline
\end{tabular}

Fonte: Dos autores (2019).

\subsection{Moldagem do APO e dos corpos de prova}

A armadura do APO foi confeccionada com o aço mola. Por isso, o grupo $\mathrm{CA}^{3}$ propôs um dimensionamento que atendesse às especificações conforme as normas do IBRACON, ao mesmo tempo que buscou-se o melhor desempenho para o protótipo, visando a utilização máxima do aço. Por isso, com a utilização do software sketchup, desenvolvemos as armaduras longitudinal e transversal. $\mathrm{O}$ 3D da armadura proposta, se encontra descriminada na Figura 1. 
Figura 1 - O 3D e a armadura executada do APO

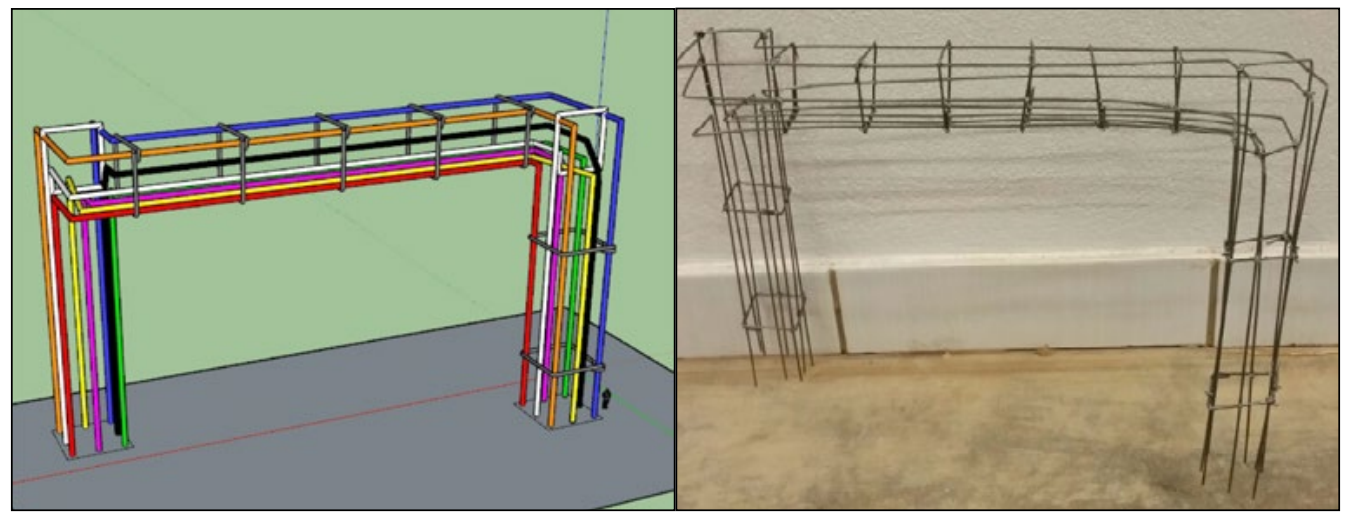

Fonte: Dos autores (2019).

A armadura do APO ficou responsável por resistir aos esforços de tração e torção. As barras da armadura respeitam o Edital do IBRACON, sendo utilizados oito fios na armadura longitudinal e dez estribos na armadura longitudinal. Os estribos foram distribuídos seis ao longo da viga e dois estribos em cada um dos pilares.

Para execução da mistura do CPR utilizou-se a argamassadeira planetária que tem a capacidade de 3 litros. Em ordem de adição, primeiramente foram inseridos os materiais granulares (areia, pó de quartzo, CP V/ARI, sílica ativa, fibra), e posteriormente os viscosos (superplastificante e água). Por fim, foram processados até obter a consistência do concreto pós reativo. Tudo isso, aconteceu no LATEC (Laboratório da Tecnologia da Construção/ Universidade do Vale do Taquari).

O processo de mistura e moldagem pode ser observado na sequência da Figura 2. Em (a) se observa as porções dos materiais secos, em (b) a forma utilizada para moldagem do APO (c) Argamassadeira dando homogeneidade ao concreto (d) moldagem e compactação do CPR e (e) desmoldagem do APO. 
Figura 2 - Sequência da moldagem a cura do APO

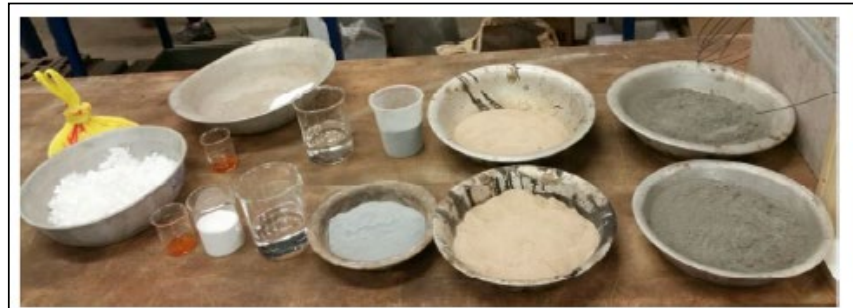

(a)

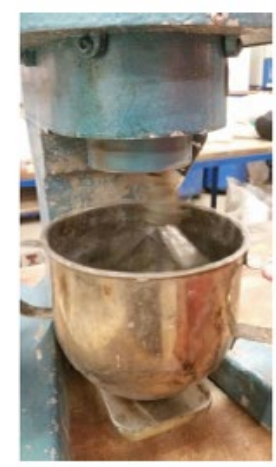

(c)

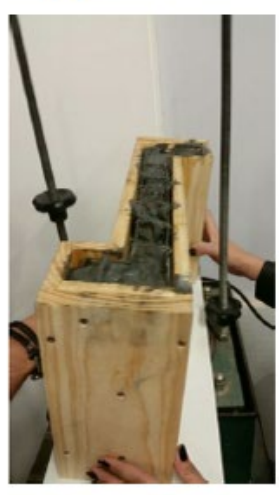

(d)

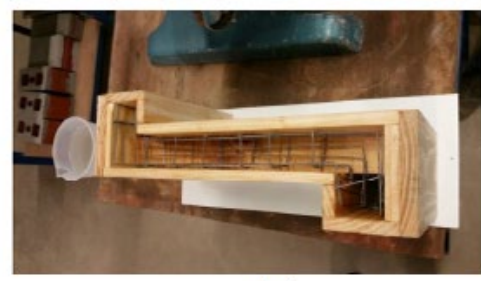

(b)

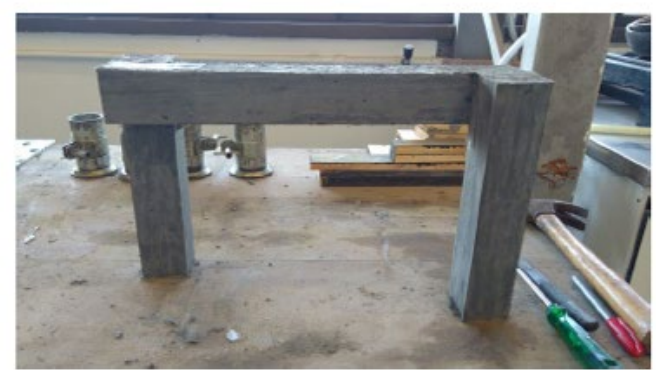

(e)

Fonte: Dos autores (2019).

A fim de verificar a resistência do concreto proposto no estudo, realizouse a montagem de dois corpos de provas conforme a Figura 3, do qual um foi rompido aos 21 dias e o segundo aos 28 dias, de modo que sendo que pudesse observar o desempenho e progresso na resistência à compressão material.

Figura 03 - APO moldado e corpos de prova

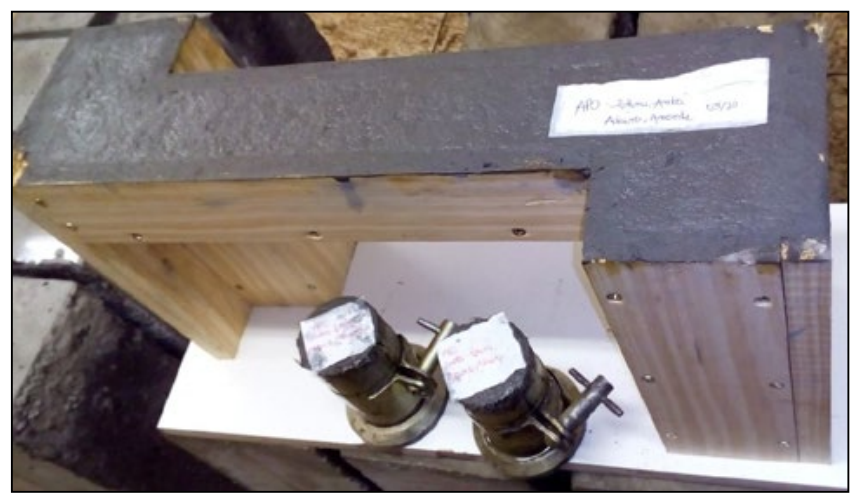

Fonte: Dos autores (2017). 


\section{RESULTADOS E DISCUSSÃO}

\subsection{Ensaio de compressão}

O ensaio de compressão ocorreu no dia 03 de outubro de 2017, nas idades dos 21 e 28 dias. Os corpos de prova foram rompidos na prensa elétrica, conforme a NBR 7215 (ABNT, 2010) - Cimento Portland - Determinação da resistência à compressão, a resistência de 59,6 Mpa aos 28 dias. Entretanto, isso não é o propósito, pois a adição de fibras não aumenta a resistência, mas gera a ponte de transferência das tensões, ou seja, gera uma distribuição mais eficiente das solicitações.

Figura 04 - Resistência à compressão do concreto

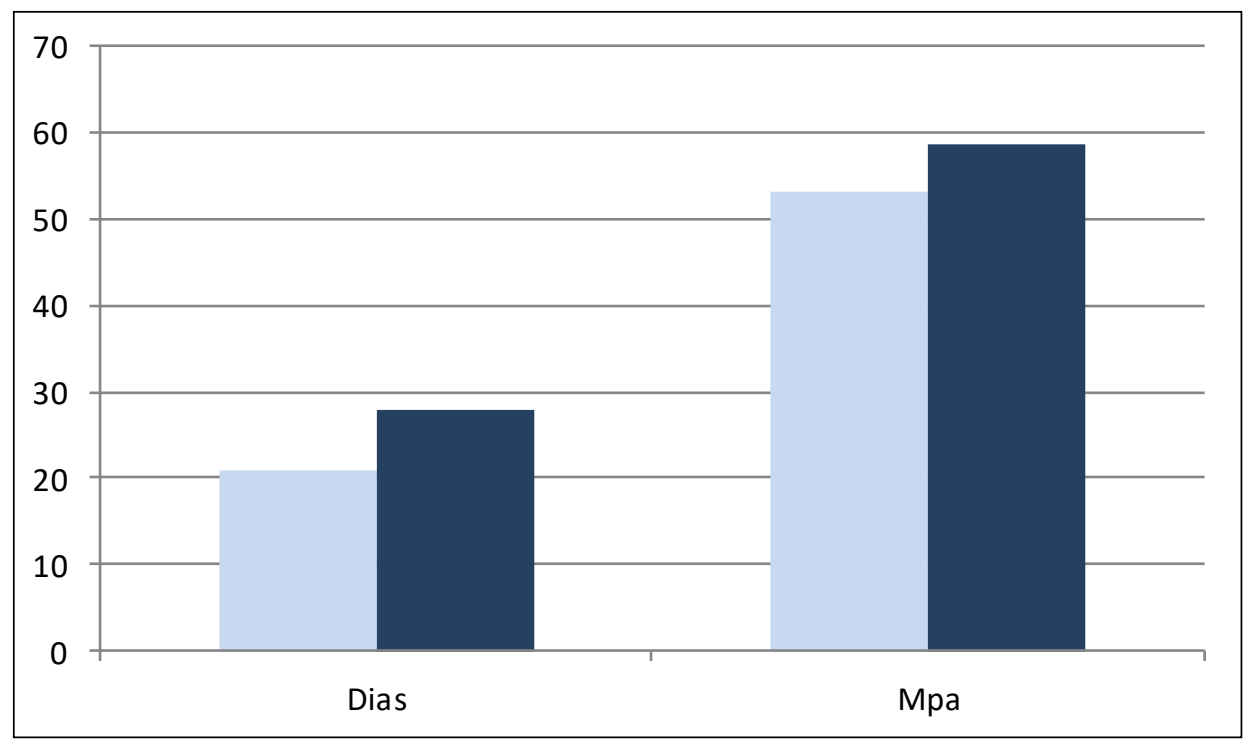

Fonte: Dos autores (2019).

\subsection{Ensaio dinâmico do APO}

O rompimento do APO ocorreu no dia 06 de outubro de 2017, durante o Technology Day do $11^{\circ}$ CETEC. O ensaio consistiu em fixar o APO, sobre uma base de madeira, preso por elástico que funcionaram como tirantes, evitando o deslocamento do pórtico. Posteriormente a fixação, o elemento do aparato foi posicionado e colocado um ovo cozido centralizado, abaixo da viga.

O corpo de prova que caia em queda livre tinha formato cilíndrico e peso equivalente a $15 \mathrm{~kg}$. As alturas que o cilindro era solto em relação ao pórtico, eram sempre crescentes, a primeira altura partiu de $0,5 \mathrm{~m}$, resistindo à essa altura de queda, o mesmo recebia golpes dos múltiplos de $0,5 \mathrm{~m}$ até a marca de 
2,5 m, quando atingido essa altura limite o APO ficava recebendo golpes até a sua ruína e o ovo se danificasse.

\subsection{Análise do APO}

No primeiro golpe o APO abriu uma fissura bem no meio da viga (Figura 5a), porém não houve desprendimento do concreto. Já na aplicação do segundo golpe a $1,0 \mathrm{~m}$ as avarias mais significativas foram na junção dos pilares/viga formação de trincas. No terceiro golpe que foi a $1,5 \mathrm{~m}$ a fissura no centro da viga aumentou e a dos pilares também, mas numa dimensão bem menor. Na altura de 2,0 $\mathrm{m}$ o pórtico começou apresentar um formato similar a letra M (Figura 5d), mas a viga se deslocou pouco. No quinto golpe que foi a 2,5 $\mathrm{m}$ a fissura do meio se acentuou bastante e a dos pilares também (Figura 5e), já no quinto e último golpe o APO foi bastante danificado, mas mesmo assim não danificou o ovo. Entretanto, no sétimo golpe o APO não resistiu, pois sua estrutura já estava comprometida, o levando a ruína (Figura 5f).

A Figura 05 mostra bem a sucessão dos impactos que o APO recebeu e seu comportamento. $\mathrm{O}$ concreto durante o ensaio de compressão na prensa elétrica não apresentou um alto desempenho, porém como na composição do mesmo tinha fibras de polipropileno à perda de material foi muito pequena.

Na Figura 05 está contida as imagens do ensaio. Na letra a) o APO está posicionado para iniciar o ensaio; b) o aparato de proteção leva seu primeiro golpe e abertura da fissura no meio; c) surgimento das fissuras na junção dos pilares com a viga; d) na altura dos 2,0 o APO começou a ter um formato similar com a letra M; e) aumento das fissuras e f) ruína do APO. 
Figura 05 - Sequência do ensaio de rompimento do APO, durante o Tecnology Day

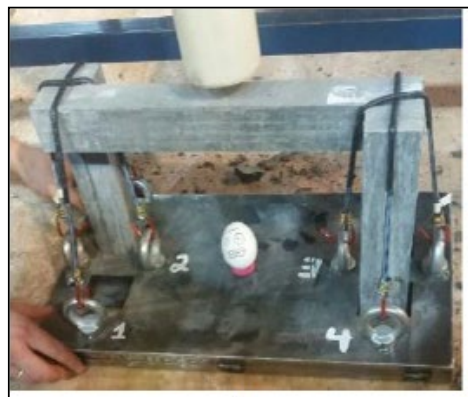

a)

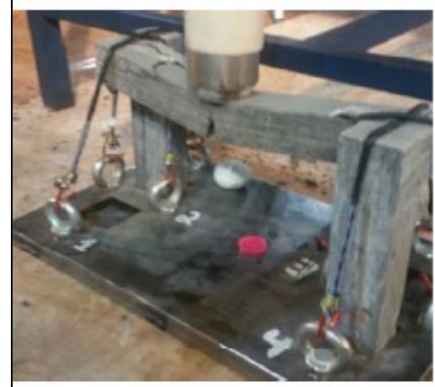

d)

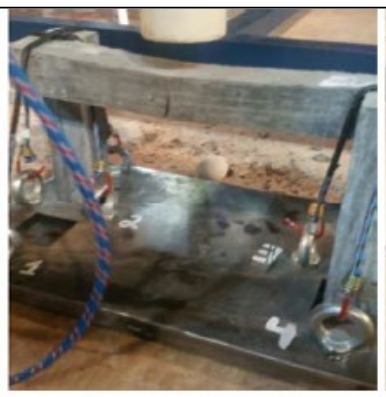

b)

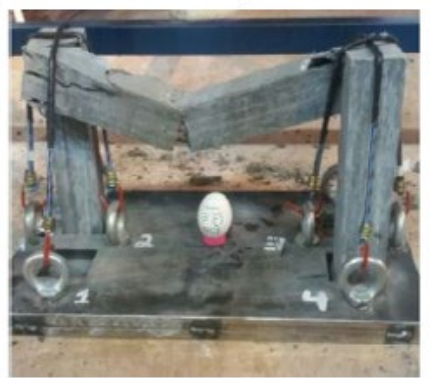

e)

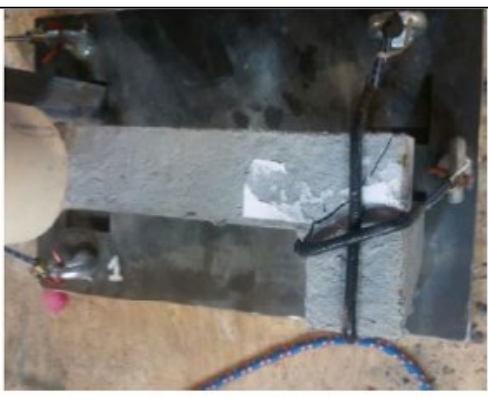

c)

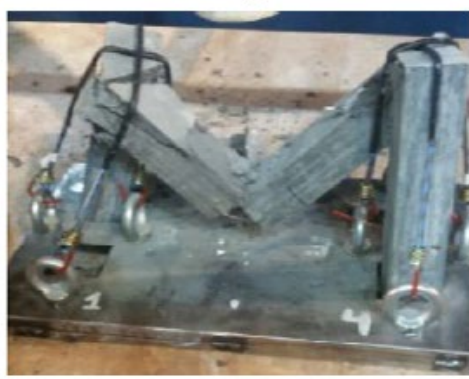

f)

Fonte: Dos autores (2019).

Ao final do ensaio o APO foi analisado criteriosamente pelo grupo CA3, para descobrir as fragilidades do projeto. A Figura 06 mostra o APO em completa ruína. O elemento desenvolvido para a competição se mostrou muito eficiente, por ficar no empate em primeiro lugar com outro grupo, mesmo não atingindo a compressão desejada, a composição concreto/aço superaram as expectativas de ter uma baixíssima perda de materiais e alta resistência ao impacto das cargas dinâmicas verticais, mesmo no caso mais extremo de 2,5 m de altura. 
Figura 06 - Análise do APO em completa ruína

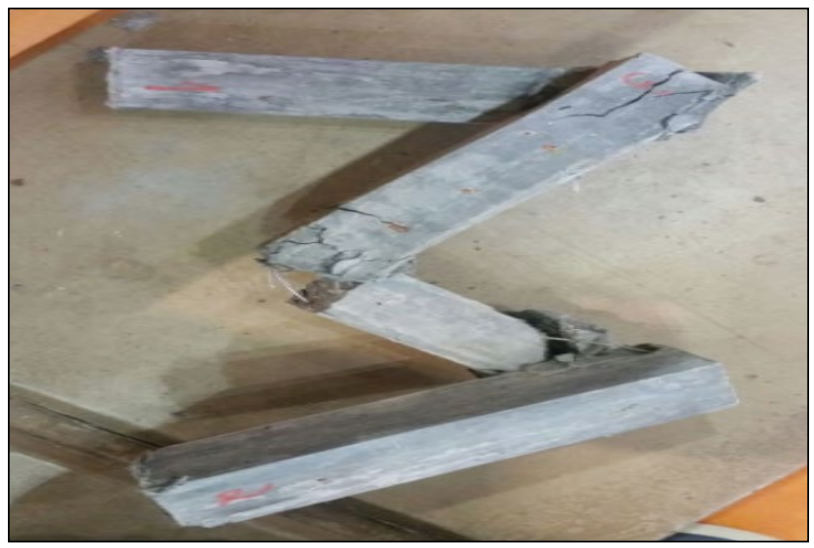

Fonte: Dos autores (2019).

O concreto teve uma característica muito significativa a de não gerar muitos resíduos durante o ensaio, quando comparado com os outros APO. Isso se deu pelo o uso das fibras que ocasionam o efeito de intertravamento no concreto, como consequência a resistência e ductilidade são elevadas consideravelmente. Outras características melhoradas são a diminuição da retração e resistência ao impacto e entre outros.

O princípio das fibras de gerar uma ponte de transferência de tensões no concreto. Por isso ficou perceptível nas fissuras abertas no APO, pois mesmo rompido as partes não se desmembravam por inteiro. Outra característica é o comportamento pseudodúctil ou seja de não ser frágil, a utilização da fibra de polipropileno assegura a menor fissuração do concreto, agindo como um obstáculo a essa patologia (SOTO, 2014).

O tipo de fibra também interfere nas propriedades desejadas do concreto, pois as características físicas, geométricas, teores e a interação da fibra com o concreto causam interferência no final. Por isso, adotou-se a fibra em fio e a de polipropileno, sendo assim uma das mais indicadas. Outros aspectos bastante relevantes para a moldagem do APO foram o lançamento e adensamento, por decorrência da distribuição e direção das fibras na matriz.

A escolha da fibra de polipropileno se deu por conta da sua alta capacidade técnica. Ou seja, a de ser extremamente compatível ao concreto nos quesitos mecânico, físico e químico. Sendo ela inerte, não absorver a água e imputrescível e de não apresentar tendência a ferrugem. Portanto, essa adição atende as necessidades, previstas em projeto.

A armadura transversal teve uma falha, que foi a de posicionar o estribo do meio com as pontas viradas para baixo, portanto o mesmo abriu. Se isso não tivesse ocorrido, o APO poderia ter validado mais um golpe a 2,5 m. Esse posicionamento favoreceu a tensão do cisalhamento. 
Outro ponto que se apresentou bem frágil, foi à junção pilares/viga. Um dos esforços percebido nessa análise foi a do momento torsor nessas duas ligações com a viga. As tensões de cisalhamento também atuaram nessa fração do APO, isso poderia ter sido evitado ou amenizado se estribos tivessem sido posicionados para combater essas tensões.

\section{Conclusão}

Com base nos resultado obtidos, pode-se concluir :

Todos os conceitos e princípios abordados em sala de aula, tiveram que ser empregados neste estudo que apresenta considerado grau de dificuldade. Pode-se também observar que a adição de fibra de polipropileno não aumenta a resistência, mas sim cria uma ponte de transferência de tensões que favorece a resistência ao impacto e também torna o elemento de concreto armado mais dúctil.

O dimensionamento da armadura longitudinal e transversal no APO foram bem assertivas. As fibras também auxiliaram nas tensões cisalhantes, e contribuíram para a minoração da perda de concreto. Pode-se também identificar que os estribos do meio deveriam estar voltados para cima. E alguns estribos deveriam estar na junção dos pilares com a viga, para combater o cisalhamento e a torção.

Esse estudo também possibilitou aos alunos da disciplina de Concreto Armado II desenvolverem o seu instinto de busca de soluções econômicas e viáveis. Sempre identificando o melhor material, que seja mais adequado para cada aplicação.

\section{Referências}

ASSOCIAÇÃO BRASILEIRA DE NORMAS TÉCNICAS. NBR 7215 - Cimento Portland - Determinação da resistência à compressão. Rio de Janeiro, 2010.

BEHLOUL, M.; BERNIER, G.; CHEYREZY, M. Tensile Behavior of Reactive Powder Concrete (RPC). In: INTERNATIONAL SYMPOSIUM OF HIGH STRENGTH/HIGH PERFORMANCE CONCRETE, 4., 1996, Paris, France. Anais...Paris. p. 1375-1381.

BONNEAU, O.; POULIN, C.; DUGAT, J.; RICHARD, P.; AITCIN, P. C. (1996).

Reactive powder concretes: from theory to practice. Concrete International. v. 18, n. 4, p. 47-49,Apr.

INEIA. A. Viabilização da substituição da areia natural pelo pó de pedra basáltica na argamassa autonivelante. Universidade do Vale do Taquari UNIVATES. Lajeado, 2017.

SOTO, N.T.A. Avaliação das propriedades do concreto de pós-reativos: um estudo de durabilidade, Curitiba, 2014. 